\title{
Model based learning of Linear Integrated Circuit Course: A practical approach
}

\author{
Shraddha $\mathrm{B} \mathrm{H}^{1}$,Subhas $\mathbf{M}^{2}$,Nikita $\mathbf{P}^{3}$,Preeti $\mathbf{P}^{4}$, Bhagyashree $^{5}$, R.M.Shet ${ }^{6}$, Jyoti $^{7}$,Nalini C Iyer ${ }^{8}$ \\ Department of Instrumentation Technology \\ B.V. Bhoomaraddi College of Engineering \& Technology, Hubli, Karnataka, India \\ 1'shraddha_h@bvb.edu, 2subhas_meti@bvb.edu, ${ }^{3}$ nikhita_patil@bvb.edu, ${ }^{4}$ Preeti_Pillai@bvb.edu, ${ }^{5}$ bhagyashree@bvb.edu, \\ ${ }^{6}$ raghu@ $v$ vb.edu, ${ }^{7}$ jyoti_patil@bvb.edu, ${ }^{8}$ nalinic@bvb.edu
}

\begin{abstract}
Transmission of knowledge present in the information by teachers does not guarantee an effective understanding of the student in a large class room which has been a greatest challenge [2], [10]. Linear integrated circuit (LIC) is analysis of solid state analog and digital devices which is characterized by infinite and finite number of possible operating states respectively. Integrated circuits play an important role in electronics. As a felicitator we have to strengthen the theoretical concepts by providing the platform for the students to model, analyze and design various applications using integrated circuits. At undergraduate level, for a large class room it is a great challenge to impart this knowledge [1]. In this paper an activity is discussed which enhances the interest of the students towards the course and depth of gaining knowledge. An effective activity called self study component was introduced at the $4^{\text {th }}$ semester level for developing the model to cater real time signal acquiring and monitoring the physical parameters. This course encouraged us to develop undergraduate level activity with the applications of data acquisition models. Findings showed that there was a significant positive difference in student's academic achievement and attitude towards learning the subject through the activity.
\end{abstract}

Keywords - Self study component, ABET, Linear Integrated Circuits, Program outcomes, SEE.

\author{
Shraddha B $\mathbf{H}^{\mathbf{1}}$ \\ Department of Instrumentation Technology \\ B.V. Bhoomaraddi College of Engineering \& Technology, \\ Hubli, Karnataka, India \\ 'shraddha_h@bvb.edu
}

\section{INTRODUCTION}

Linear integrated circuit is the fundamental course for Electrical, Electronics and Instrumentation students. Since there is a rapid growth in the field of VLSI, integrated circuits are in huge demand. It became evident that students have to learn the overall concept of LIC course thoroughly as it is the part of electronics which they use day in and day out like computers, mobile phones, and tablets so on. In this course the students are guided with theoretical concepts of various integrated circuits and their applications which have related mathematical representations and proofs with supporting theorems and definitions. There is also an associated laboratory for the students in the same semester named signal handling and data acquisition (SHDA) which focuses on acquiring the physical parameters using sensors and signal conditioning the same using discrete components and integrated IC's. One of the major integrated circuit is learnt in the course is operational amplifier commonly known as OPAMP. There was a gap observed in this course as students were having the knowledge as a part of their discipline and were not aware of how to apply this knowledge in real time scenario. Most of them read the concepts dealt in the course and just represent them in the exams as the students are exam centric. Students learn different courses as black box without correlating them [6]. Hence a self study component was framed to provide a platform for the students to solve a real world problem and build a DAQ model on PCB. The following activity catered an integrated experience of courses learnt by the students in their third semester like Electronic measurements for instrumentation (EMI) and fourth semester like LIC, SHDA laboratory and ARM course. The flow of the activity was planned in such a way that the concepts dealt in EMI on sensor characterization is used to solve the problem, prototype model is built consisting of signal conditioning circuit ,microcontroller and display unit.

The following learning objectives were considered during implementation of this activity

- To be aware of using the learning concepts for analysis and synthesis of discrete and integrated circuits. 
- To improve the analytical power of students and provide better understanding of theoretical concepts.

- To improve the ability of the students to design, develop and model electronic systems based on integrated circuits under realistic conditions.

This paper presents an activity that can help the students to correlate the theoretical knowledge of the concepts dealt in class and practical knowledge dealt in the laboratory to solve a real world problem.

Organization of the paper is as follows, Section 2 deals with the Methodology, Section 3 discusses about implementation details of activity and assessment, Section 4 deals with experimental outcomes and discussion, Section 5 deals with effectiveness of the activity, and Section 6 deals with conclusion.

\section{Methodology}

Conventional teaching method like chalk and talk, giving assignments to the students and so on will not provide the analysis of the concepts being learnt in the large class room. Hence an activity called self study component was introduced in the course. This activity was framed in such way that the students had to integrate the knowledge of sensors, integrated IC's and programming skills in order to have the complete design analysis and build a model to display the physical parameter. Linear integrated circuit, Signal Handling and Data Acquisition Laboratory and ARM programming were the fundamental courses dealt in the fourth semester of the curriculum; utilizing all these courses an activity was modeled. The details of the activity are been discussed below:

- Group Formation and identification of physical parameter: The students are motivated to work in a group at the early semester stages so that they learn to work in a team. In this group the task given to them is to do a survey of the physical parameters which are monitored around their premises and choose one physical parameter for which they will be designing a model

- Concept analysis for design: In this stage the students have to choose a sensor applicable for the physical parameter chosen by them and analyze the datasheets of the same. They also have to go through the concepts dealt in the class [2] and arrive at the functional block diagram with several integrated circuits required for the signal conditioning the signal and other components to be used in the prototype. A circuit diagram has to be developed based on the design.

- Simulation Stage and Bread board implementation: In this stage the students performed analysis of the circuit diagram using Electronic design automation/integrated development environment tool to check the functional working of the design and have iterative steps for captivating corrective actions to improvise with the design. After simulating the design in a tool the students implemented the circuit on bread board using discrete and integrated components and checked for the functionality.

- $\quad$ PCB design implementation: In this stage the students have to design the Printed circuit board of their designed circuit and validate the model once again.

- Extended Learning: This activity provides the students with qualitative and quantitative analysis which will lead them to apply this experience beyond curriculum.

- Report Writing: Information collected is organized for meaningful interpretation and analysis and submitted in the form of report, reflecting all the activity details including sensor characterization details and snaps/videos of the built prototype DAQ model.

\section{IMPLEMENTATION}

There were several reviews the students had to pass through the session of completion of the activity so that they were provided with the necessary guidance of the design process under realistic trade off conditions. Every ten days the progressive growth was observed through presentation by the team. Groups have to co-ordinate, organize, distribute the work among the team members and prepare the PPT showcasing the progress of their activity. This activity helped the students to correlate and integrate the concepts learnt in different courses and apply it to solve the real world problem.

The following road map was developed to carry out the activity:

- Review 1Literature survey phase: where the students went through different processes in industry either by visiting nearby industry or through the net and jotted down different physical parameters which are been monitored in the industry. Some of the parameters are Temperature, Pressure, Distance, Weight, Number of rotations by an object, Alcohol consumption detection, Color detection, Moisture detection and so on. Group has to choose one physical parameter and select a sensor and analyze its features, cost and other electrical parameters.

- Review 2 Design on paper, Simulation Phase and bread board implementation: students are reviewed for their approach to solve the problem with design of a circuit diagram and validating the design through the usage of simulating tool. The main advantage of simulating is that it provides strong virtual laboratory environment, easy to build or modify the circuits in simulation tool, easy modification of various parameters and observe the outcome of the circuit.

- $\quad$ Review 3 PCB Design and validation phase: students are reviewed for the PCB design of their bread board implementation and demonstration of their prototype DAQ system [5] by interfacing various discrete components and integrated IC's with microcontroller 
and monitor the physical parameter on the display unit. Each review is associated with presentations so that the students develop in their presentation skills.

Contents of Table 1 indicate various sensors the students have worked with to build a prototype DAQ model.

\begin{tabular}{|ll|}
\hline Table 1 List of sensors \\
\hline 1. & LM35 Temperature Sensor \\
\hline 2. & Strain gauge Pressure Sensor \\
\hline 3. & Alcohol Sensor \\
\hline 4. & IR Sensor \\
\hline 5. & Ultrasonic Sensor \\
\hline 6. & Groove Sensor Soil Moisture Sensor \\
\hline 7. & TCS230 Color Sensor \\
\hline 8. & RTD Temperature Transducer \\
\hline 9. & Tachometer \\
\hline
\end{tabular}

Case Studies:

1. Details showcasing the process of sensor charactization and block diagram implementation.

- Parameter: Soil moisture

- Sensor used- ROBO-MART Soil moisture sensor

Study of sensor characteristic was done with various different kinds of soil for example wet soil, dry soil and half wet soil. Connection of the sensor was made based on the datasheet for voltage rating, current rating and other parameters and tabulation was made. Figure 1 shows the sensor characterization done using soil and table 2 shows the tabulation done for various types soils. The block diagram implementation is shown in figure 2.

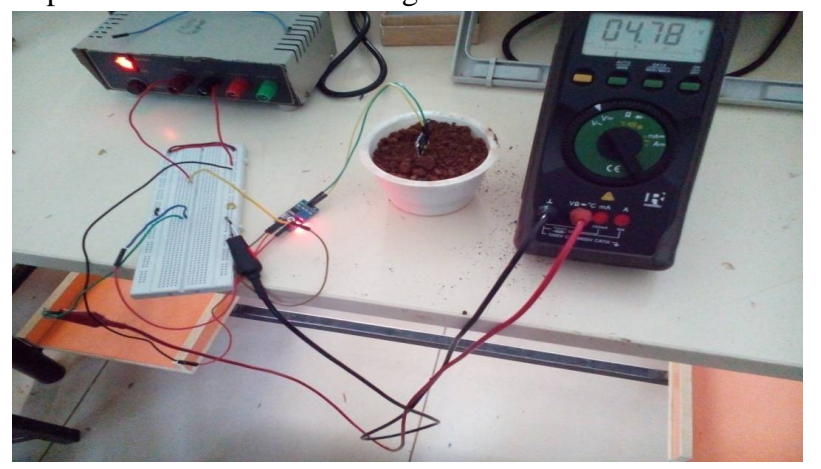

Fig 1: Sensor output realization for different test inputs Table 2: Tabulation of the sensor Output

\begin{tabular}{|l|l|l|}
\hline S.NO & Content of water in soil & $\begin{array}{l}\text { Voltage } \\
\text { readings }\end{array}$ \\
\hline 1. & Fully dry soil & 4.83 \\
\hline 2. & $\begin{array}{l}\text { Presence of } 5 \mathrm{ml} \text { of water in } \\
\text { soil. }\end{array}$ & 1.73 \\
\hline 3. & $\begin{array}{l}\text { Presence of } 10 \mathrm{ml} \text { of water in } \\
\text { soil. }\end{array}$ & 1.228 \\
\hline 4. & $\begin{array}{l}\text { Presence of } 15 \mathrm{ml} \text { of water in } \\
\text { soil. }\end{array}$ & 1.048 \\
\hline 5. & $\begin{array}{l}\text { Presence of } 20 \mathrm{ml} \text { of water in } \\
\text { soil. }\end{array}$ & 0.971 \\
\hline 6. & $\begin{array}{l}\text { Presence of } 25 \mathrm{ml} \text { of water in } \\
\text { soil. }\end{array}$ & 0.933 \\
\hline 7. & $\begin{array}{l}\text { Presence of } 30 \mathrm{ml} \text { of water in } \\
\text { soil. }\end{array}$ & 0.904 \\
\hline
\end{tabular}

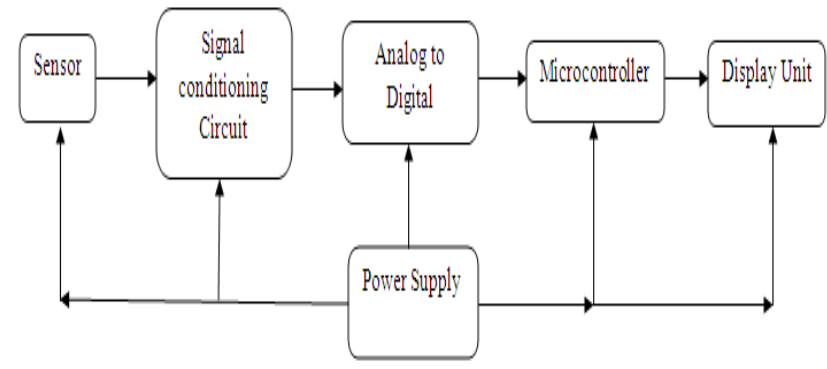

Fig 2: Block diagram Implementation

Observing the voltage reading variations based on water content in soil, the students concluded that as the water content is increasing in the soil the voltage of the sensor is dropping. They use this analysis for the development of the prototype.

2. Details showcasing the block diagram simulation of the circuit diagram designed and bread board implementation.

- Parameter-Object counter.

- Sensor used-IR sensor.

Figure 3 shows the simulation of circuit diagram which consists of discrete as well as integrated components and microcontroller. Students wrote a program and dumped in the tool and gave the inputs manually to validate the working or their design. Simulation of the designed circuit diagram was done in an Electronic design automation tool. Figure 4, 5 and 6 shows the bread board implementation of the circuit diagram simulated for validation with the sensor.

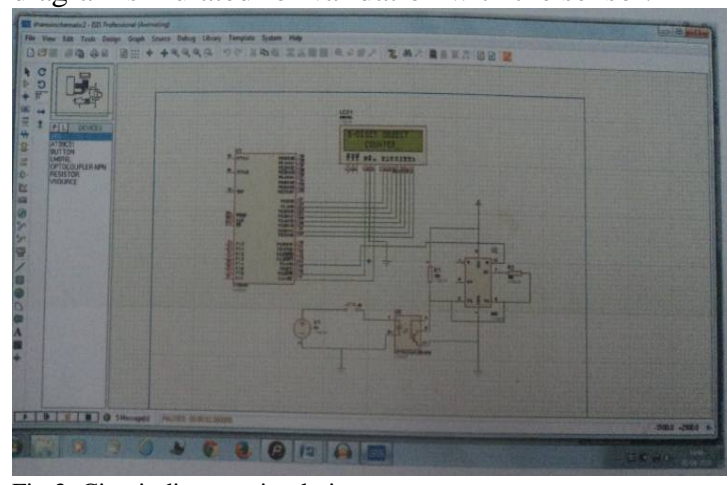

Fig 3: Circuit diagram simulation

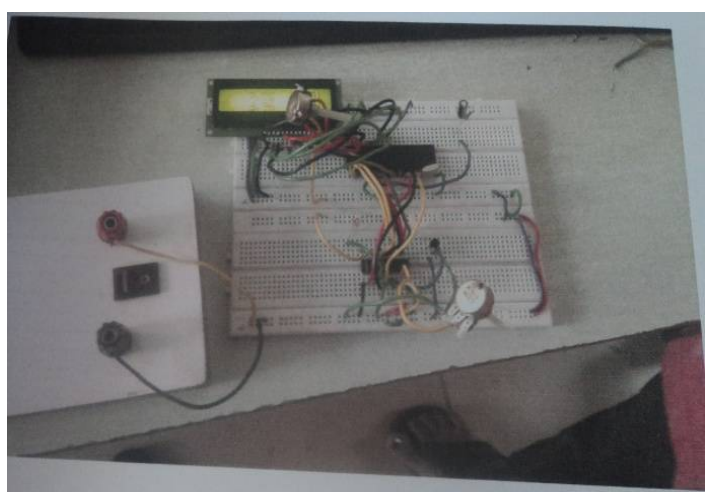

Fig 4: Bread board implementation 


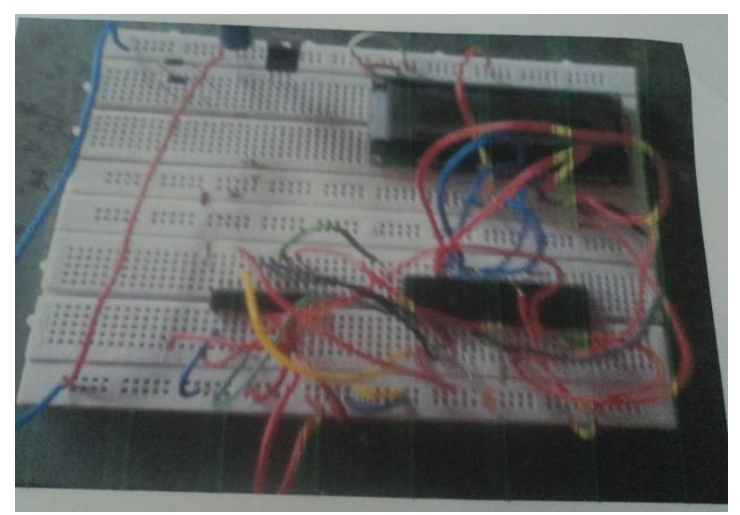

Fig 5: Bread board implementation

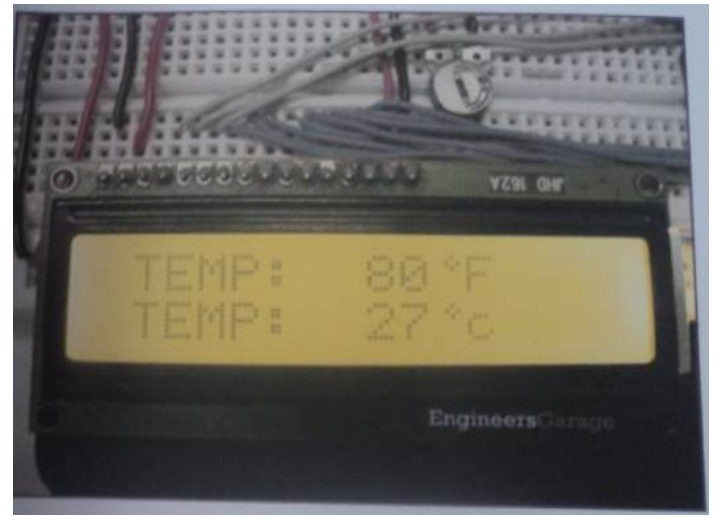

Fig 6: Bread board implementation with display unit

3. Details showcasing the PCB implementation of the circuit diagram designed with microcontroller and other components for building the prototype.

- Parameter: Temperature Measurement

- Sensor used: LM35 temperature sensor

Figure 6 shows the PCB of temperature display system which uses seven segment display component as the display unit.

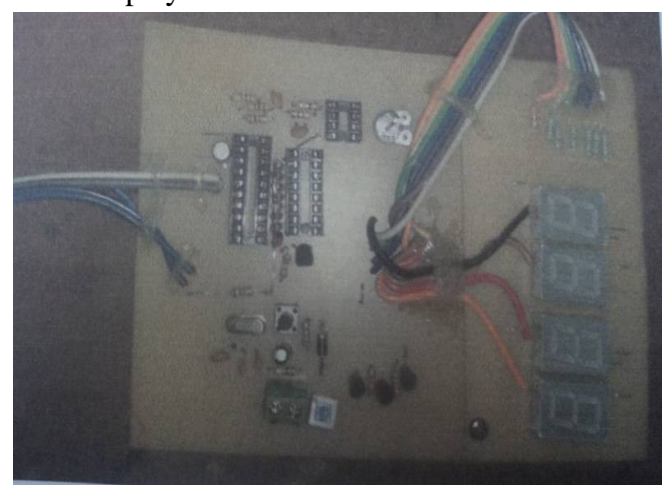

Fig 6: PCB implementation

4. Images of different DAQ prototype models build by the students.

Figure 7 shows the DAQ model for the distance measurement and obstacle detector using ultrasonic sensor. The buzzer is used as an actuating component which will alert the presence of obstacle.

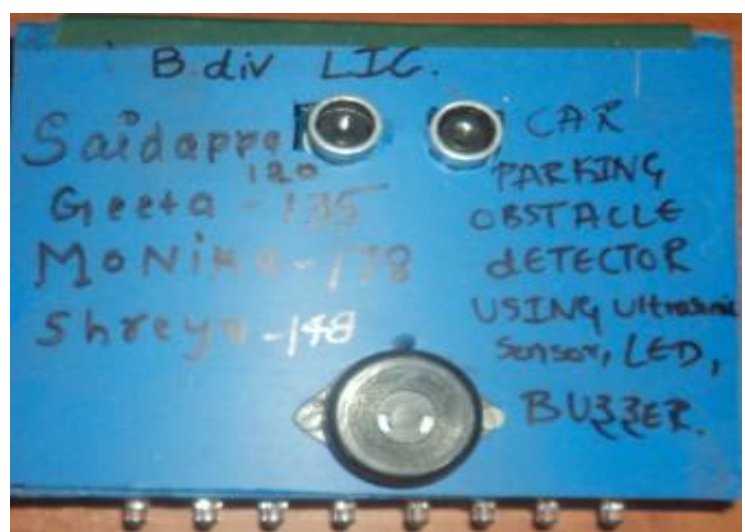

Fig 7: Prototype DAQ model for parking obstacle detection Figure 8 shows the DAQ model for PIR to detect the presence of hand and regulate the flow of air.

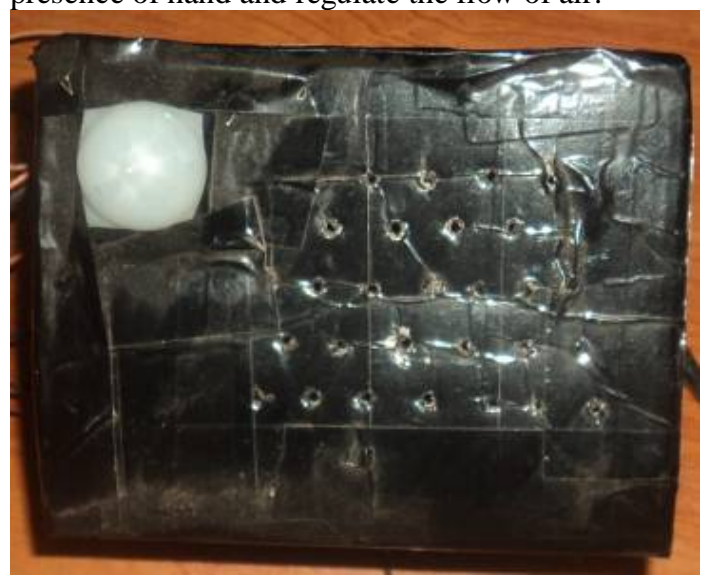

Fig 8: Prototype DAQ model for PIR sensor.

\section{ASSESSMENT}

The assessing methods of the activity included students individual contribution and in the group. The assessment criteria for evaluating the performance of the students are as shown in Table. 3. This activity motivated the students to apply the concepts learnt in class and practical sessions done in the laboratory by stitching different courses and solving a problem which is the minimum requirement of being an engineer.

Table 3Assessment rubrics

\begin{tabular}{|l|l|l|}
\hline S.No & \multicolumn{1}{|c|}{ Assessment Criteria } & Weight-age \\
\hline 1. & $\begin{array}{l}\text { Physical Parameter chosen and Sensor } \\
\text { Characterization using datasheet. }\end{array}$ & $30 \%$ \\
\hline 2. & $\begin{array}{l}\text { Analysis of the Sensor, design and } \\
\text { ability to arrive at the circuit diagram. } \\
\text { Simulation analysis and validation of } \\
\text { the circuit design. }\end{array}$ & $25 \%$ \\
\hline 3. & $\begin{array}{l}\text { Arriving at the bread board } \\
\text { implementation. }\end{array}$ & $15 \%$ \\
\hline 4. & $\begin{array}{l}\text { Arriving at the PCB implementation } \\
\text { and demonstration of the DAQ system }\end{array}$ & $30 \%$ \\
\hline
\end{tabular}

\section{EFFECTIVENESS OF THE ACTIVITY}

The effectiveness of the activity has been assessed through the student's performance performed in the semester end exams of academic year 2013-14 to the academic year 2014-15 and feedback provided by the students. The 
feedback was collected by the students. By doing this activity the students had an integrated experience of different courses and were able to deal with real time parameters.

Feedback Questionnaires for this activity is listed in Table. 4

Table 4 Questionnaires For Student Feedback

\begin{tabular}{|l|l|}
\hline S.No & Questions \\
\hline 1. & $\begin{array}{l}\text { Did this activity enhance the purpose and } \\
\text { justification towards learning the concepts in } \\
\text { different courses? }\end{array}$ \\
\hline 2. & $\begin{array}{l}\text { After this activity how do you rate the understanding } \\
\text { level of the course? }\end{array}$ \\
\hline 3. & $\begin{array}{l}\text { Did this activity motivated you have the self study } \\
\text { experience. }\end{array}$ \\
\hline 4. & Did technique inspire you for collaborative learning? \\
\hline 5. & Any other comments \\
\hline
\end{tabular}

Question 1 relates to whether the students found this activity motivating enough to learn the concepts of different courses and try to integrate them to solve a real world problem. In response students found it very interesting to solve the problem statement and build a prototype of DAQ system by integrating various courses. Question 2 reflects on the improvement on understanding of the concepts in the course and in response 93\% students agreed that this learning method helped them to increase their understanding capability of how things work in real scenario by having hand's on experience of using the concepts learnt in the class. After completion of this activity $89 \%$ students agreed that this technique helped them in developing self learning skills for solving a given problem and improving them in their presentation skills which is reflected in question 3.For question $4 \& 5$, an achievement of $90 \%$ is observed to justify better understanding of the concept and enhancement in collaborative learning as shown in Figure 8.

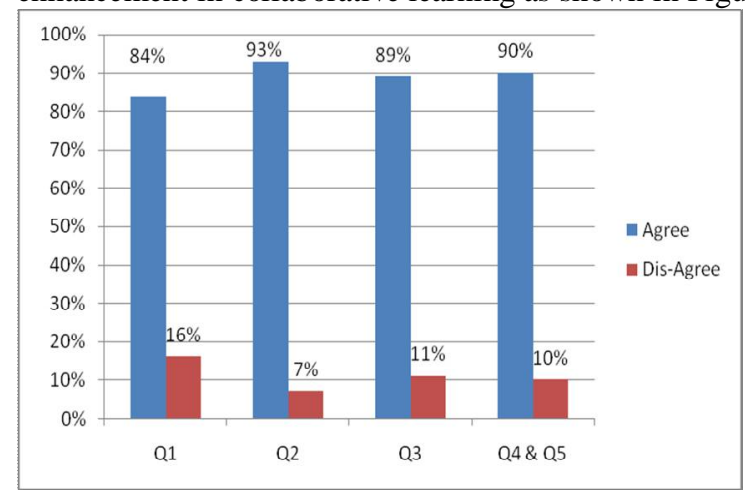

Fig 8: Feedback Summary of activity by students

The effectiveness of the progressive activity has been reflected in the performance of students. The performance of students in the academic year 2013-14 for LIC course is compared with the performance of the students in the academic year 2014-15 and is observed that the percentage of the class result is increased as shown in Figure 9.

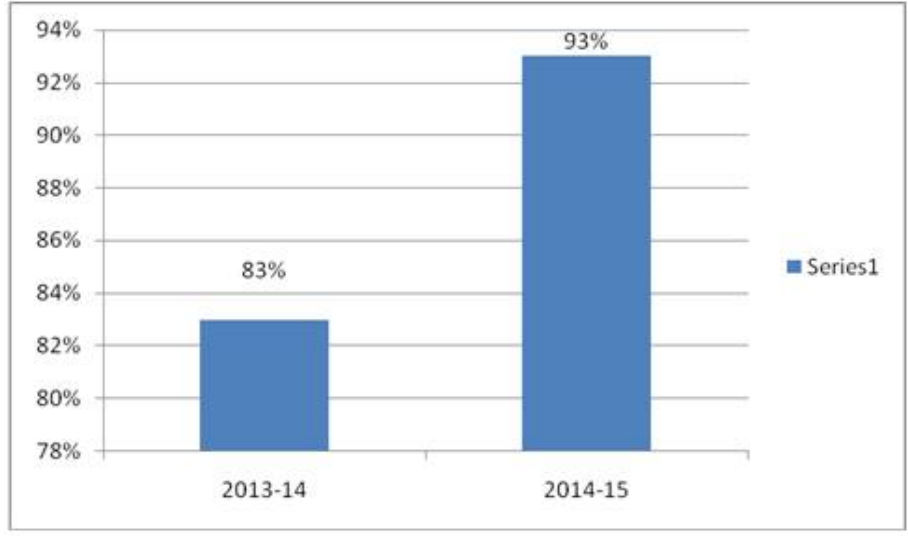

Fig. 9: Comparison of results

\section{EXPERIMENTAL OUTCOMES AND DISCUSSION}

The results and outcomes of the activity is mapped to the learning outcomes a to $\mathrm{k}$ of Accreditation Board for Engineering and Technology (ABET) [9] criteria as shown in Table 5.

Table 5 Activity outcomes mapping to ABET program outcomes

\begin{tabular}{|c|c|c|}
\hline Steps & $\begin{array}{l}\text { Performance indicators } \\
\text { attaining the Program } \\
\text { outcomes }\end{array}$ & $\begin{array}{ll}\text { Program } & \\
\text { outcomes } \quad \mathrm{a}-\mathrm{k} \\
\text { criteria's } \\
\text { addressed }\end{array}$ \\
\hline $\begin{array}{l}\text { Concept } \\
\text { Analysis }\end{array}$ & $\begin{array}{l}\text { Applying the knowledge } \\
\text { of engineering } t \text { develop } \\
\text { a circuit diagram trough } \\
\text { design analysis and have } \\
\text { a better understanding of } \\
\text { the concept. }\end{array}$ & $\mathrm{a}$ \\
\hline $\begin{array}{l}\text { Design } \\
\text { Analysis }\end{array}$ & $\begin{array}{l}\text { Ability to solve a given } \\
\text { problem and design a } \\
\text { component }\end{array}$ & $\mathrm{c}$ \\
\hline Team work & $\begin{array}{l}\text { Ability to define roles and } \\
\text { responsibilities of team } \\
\text { members. } \\
\text { Ability to contribute } \\
\text { effectively to the team } \\
\text { discussions. }\end{array}$ & d \\
\hline $\begin{array}{l}\text { Extended } \\
\text { Learning }\end{array}$ & $\begin{array}{l}\text { Awareness about the } \\
\text { importance of learning } \\
\text { beyond curriculum using } \\
\text { technical library } \\
\text { resources, interacting } \\
\text { with experts and } \\
\text { participating in technical } \\
\text { events. }\end{array}$ & $\mathrm{i}$ \\
\hline Presentation & $\begin{array}{l}\text { To improve Oral and } \\
\text { Written communication }\end{array}$ & g \\
\hline Soft Skills & $\begin{array}{l}\text { Ability to use EDA tools } \\
\text { for modeling and } \\
\text { simulation. }\end{array}$ & $\mathrm{k}$ \\
\hline
\end{tabular}

Activity as a learning technique is mapped to the learning outcomes a to $\mathrm{k}$ of Accreditation Board for Engineering and Technology (ABET)[8] criteria. The 
attainment of Program outcomes through performance indicators is shown in the Figure 10. By the graph shown in figure 10 we can infer that by adopting this learning centric method we are able to achieve the outcomes c, d, i, g, k. A number of improvement points have been identified through this measurement. The students ability to solve a real world problem through therotical concepts has been addressed and fostered.

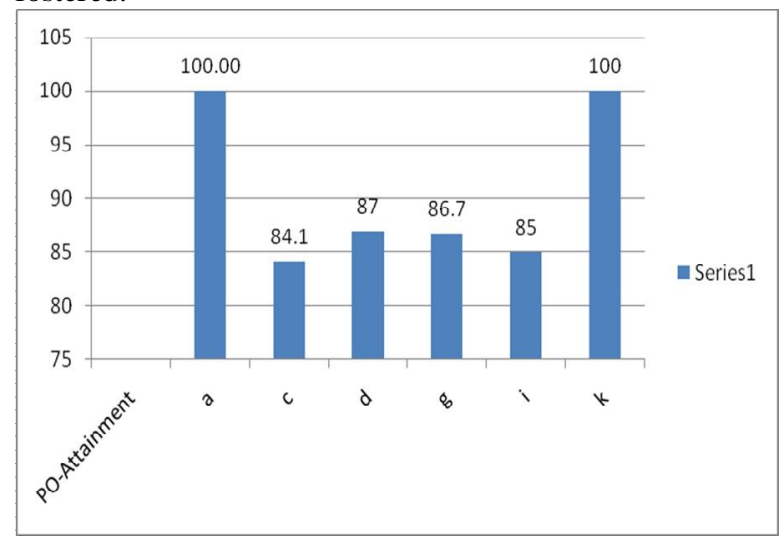

Fig 10:Program Outcomes Attainment through Performance Indicators.

\section{CONCLUSION}

The objective behind framing this activity was successfully achieved.The students were able to experience and improvise in model building,intergration of various courses and applying them in solving real world problems, presentation skills, working ability in group. As this is a mathemitically oriented theorotical subject, students were motivated to learn the course through real world eperience and its analysis. The most prominent positive outcome of the experiment is that over $90 \%$ of the students have clearly indicated that this has given them a very good opportunity to evaluate, work on and improve their conceptual learning method.

This interactive learning approach adopted has great impact in significantly improving the overall teaching learning process, encouraging the faculty and the students to extend the same to the relevant courses in the curricula program. By this activity we were able to attain the ABET[8] criteria a, $\mathrm{c}, \mathrm{d}, \mathrm{i}, \mathrm{g}, \mathrm{k}$ whereas before this subject was only able to attain a. In this paper, the authors have proposed a new framework for teaching LIC course through practical experience based learning which will help them to carry out the projects and also used integrated experience to demonstrate how some of experiment can be simulated and studied outside the scope of course and laboratory[4]. This approach improves the performance and response of students in teaching and learning. In net shell, this pedagogical activity can be used profitably in the analysis of any problem related to integrate IC's
REFERENCES

[1] Rajender Kumar and Krishan Kumar " PSPICE and MATLAB/SimElectronic Based Teaching of Linear Integrated Circuit: A New Approach"

[2] B Shraddha,Raghavendra Shet, Nikita P"Mind Mapping: An Useful Technique for Effective Learning in Large Classroom"

[3] Thomas, JW, (2000) "A review of research on project based learning".

[4] Thomas, J.W., Mergendoller, J.R., \&Michaelson, A. (1999) "Project Based Learning: A handbook for middle and high school teachers". Novato, CA: The Buck institute for Education

[5] Preeti Pillai "Prototype Implementation: An Effective Learning Method in Process Automation".

[6] B Shraddha "Tutorial: A Case Study on Integrated Learning".

[7] Jennifer M. Case , Gregory Light, 'Emerging Methodologies in Engineering Education Research' Journal of Engineering Education January 2011, Vol. 100, No. 1, pp. 186-210

[8] http://www.abet.org/special-reports/

[9] http://cft.vanderbilt.edu/teachingguides/pedagogical/bloomstaxonomy/

[10] Edward F. Redish, Karl A. Smithg ,'Looking Beyond Content:Skill Development For Engineers' unpublished 